\title{
A polysaccharide component from Strongylocentrotus nudus eggs inhibited hepatocellular carcinoma in mice by activating $\mathrm{T}$ lymphocytes
}

\author{
MIN ZHANG* , YANG LIU* , JINGWEN LI* , MENGYUN KE, JIE YU, JIE DOU, HUI WANG and CHANGLIN ZHOU \\ State Key Laboratory of Natural Medicines, School of Life Science and Technology, \\ China Pharmaceutical University, Nanjing, Jiangsu 210009, P.R. China
}

Received July 27, 2015; Accepted September 27, 2016

DOI: $10.3892 / \mathrm{ol} .2017 .5624$

\begin{abstract}
A component purified from Strongylocentrotus nudus eggs on a diethylaminoethyl cellulose-52 chromatography column and eluted using a $\mathrm{NaCl}$ solution gradient (SEP-S), is a homogeneous polysaccharide of $\alpha$-D-glucan with a reduced molecular weight of $9.33 \times 10^{5} \mathrm{Da}$, compared with that of $S$. nudus egg polysaccharide (SEP). In an in vivo antitumor assay of histocompatibility-22 hepatocellular carcinoma in tumor-bearing mice, the inhibitory rates at SEP-S doses of 5,10 and $20 \mathrm{mg} / \mathrm{kg} /$ day were $38.8,50.7$ and $70.3 \%$, respectively. In addition, the spleen and thymus indices and the percentages of cluster of differentiation (CD) $4^{+}$and $C D 8^{+} \mathrm{T}$ cells were significantly increased, and the activity of cytotoxic T lymphocytes was notably enhanced, suggesting that the anti-hepatocellular carcinoma activity is mediated by boosting the immune system. In vitro experiments also demonstrated that splenocyte proliferation induced by SEP-S was inhibited by the toll-like receptor (TLR) 2 and TLR4 monoclonal antibodies. These data indicate that SEP-S is a polysaccharide component possessing high anti-hepatocellular carcinoma activity and may be a potential immunotherapy candidate for the treatment of liver cancer.
\end{abstract}

\section{Introduction}

Polysaccharides are currently the subject of numerous biochemical and nutritional studies as modifiers of biological

Correspondence to: Professor Changlin Zhou, State Key Laboratory of Natural Medicines, School of Life Science and Technology, China Pharmaceutical University, 24 Tong Jia Xiang, Nanjing, Jiangsu 210009, P.R. China

E-mail: cl_zhou@cpu.edu.cn

${ }^{*}$ Contributed equally

Keywords: Strongylocentrotus nudus egg polysaccharide, antitumor activity, hepatocellular carcinoma, T lymphocyte activation, toll-like receptor responses, due to their various biological activities and use in medicine and health foods (1). Numerous natural polysaccharides and polysaccharide-protein complexes obtained from various organisms, including algae, plants, microorganisms and animals $(2,3)$, have been demonstrated to possess significant antitumor, anti-radiation, antioxidant, anti-human immunodeficiency virus and immunostimulatory activities $(4,5)$, as well as relatively low toxicity (6). Strongylocentrotus nudus (S. nudus) roe is a form of seafood in China; according to traditional Chinese medicine, consumption of $S$. nudus may prevent cardiovascular diseases and enhance immunity $(7,8)$. Previous studies have revealed that polysaccharides in $S$. nudus eggs are able to activate immunocytes, including lymphocytes, macrophages and natural killer (NK) cells (9-13). A previous study isolated a polysaccharide, known as SEP, from $S$. nudus eggs using diethylaminoethyl cellulose (DEAE)-52 column purification and elution with distilled water; SEP was well-characterized and demonstrated to be a potent immunomodulatory agent (9). Notably, a polysaccharide fraction named SEP-S was identified when the cellulose DEAE-52 anion exchange column was eluted using $\mathrm{NaCl}$ solutions of increasing ionic strength, following SEP purification and elution with distilled water (9).

According to previous studies, SEP is a D-glucan containing an $\alpha$-1, 4-linked backbone and $\alpha$-1, 6-linked branches; it is able to activate splenocytes and prevent the growth of Sarcoma 180, histocompatibility complex-22 (H22) hepatocellular carcinomas and Lewis lung cancer, by promoting $\mathrm{T}$ cell proliferation and differentiation into cytotoxic $\mathrm{T}$ lymphocytes (CTLs) and enhanced NK-mediated cytotoxicity to tumor cells in vivo $(10,11)$. Additionally, SEP exerts a variety of immune regulatory functions, consisting of promotion of cytokine secretion and antibody production $(12,13)$.

In the present study, a salt-eluted polysaccharide fraction (SEP-S) from S. nudus eggs was identified and it's antitumor and immunoregulatory activities were investigated, to the best of our knowledge, for the first time using the $\mathrm{H} 22$ tumor-bearing mouse model. SEP-S is a homogeneous polysaccharide of $\alpha$-D-glucan, with a reduced molecular weight of $9.33 \times 10^{5} \mathrm{Da}$, compared with SEP. The present study also assayed the biological effects of SEP-S on murine hepatocarcinoma using $\mathrm{H} 22$ tumor-bearing mice, on the immune system, including $\mathrm{T}$ 
subsets and toll-like receptors (TLRs) in spleen lymphocytes. The current study therefore demonstrates the purification and characterization of a polysaccharide component, SEP-S, which exerts effective anti-hepatocarcinoma activity in vivo by enhancing the function of the host immune system.

\section{Materials and methods}

Cell lines, mice and reagents. The cell lines used in the present study, consisting of A549 human non-small cell lung cancer, HepG2 human hepatocellular carcinoma, H22 mouse hepatocellular carcinoma, B16 mouse melanoma and MDCK Madin-Darby canine kidney, were purchased from the American Type Culture Collection (Manassas, VA, USA). Cells were cultured at $37^{\circ} \mathrm{C}$ in a humidified atmosphere containing $5 \%$ $\mathrm{CO}_{2}$ in RPMI-1640 medium or Dulbecco's modified Eagle's medium (DMEM) supplemented with $10 \%$ fetal bovine serum, $100 \mathrm{U} / \mathrm{ml}$ of penicillin and $100 \mathrm{U} / \mathrm{ml}$ of streptomycin (Gibco; Thermo Fisher Scientific, Inc., Waltham, MA, USA).

Male imprinting control region (ICR) mice between 6 and 8 weeks of age (weight, $18 \pm 2 \mathrm{~g}$ ) were purchased from the Laboratory Animal Center of Yangzhou University (Yangzhou, China) and acclimatized for 1 week prior to use. Animals were provided with continuous standard rodent chow and water and were housed in a rodent facility at $22 \pm 1^{\circ} \mathrm{C}$ with a $12 \mathrm{~h}$ light-dark cycle. All procedures involving animals and their care in this study were in strict accordance with protocols of the Ethics Committee of China Pharmaceutical University (Nanjing, China).

Concanavalin A and fluorescein-5-isothiocyanate (FITC) were purchased from Sigma-Aldrich (Merck Millipore, Darmstadt, Germany). Injectable cisplatin and 5-Fluorouracil (5-Fu) were obtained from Qilu Pharmaceutical Co., Ltd. (Jinan, China) and Tianjin Jinyao Amino Acid Co., Ltd. (Tianjin, China), respectively. The antibodies specific to TLR2 (anti-TLR2; \#16-9021; $1 \mathrm{mg} / \mathrm{ml}$; dilution, 1:100) and TLR4 (anti-TLR4; \#14-9924; $0.5 \mathrm{mg} / \mathrm{ml}$; dilution, 1:50) were obtained from eBioscience, Inc. (San Diego, CA, USA).

Isolation and purification of SEP-S. S. nudus were collected from the Huang Hai Sea, China and transported to the laboratory packed in ice. The shell, spine and intestine were immediately removed, and the eggs were stored at $-20^{\circ} \mathrm{C}$. Crude polysaccharide was isolated from the $S$. nudus eggs and additionally purified as described previously (9). Briefly, the dried $S$. nudus eggs $(60 \mathrm{~g})$ were first treated with acetone $(\mathrm{w} / \mathrm{v}, 1: 1,600 \mathrm{ml} \times 3)$ to remove fat and pigments. The pellets were extracted with distilled water $(600 \mathrm{ml})$ at $90^{\circ} \mathrm{C}$ every $6 \mathrm{~h}$, a total of 3 times. The supernatants were collected by centrifugation at $1,900 \mathrm{x} g$ for $15 \mathrm{~min}$ and concentrated under vacuum. The concentrated solution was deproteinated using the Sevag method (14). The crude polysaccharide fraction was obtained through precipitation with a 5-fold volume of ethanol and desiccation in vacuo. The precipitate $(0.2 \mathrm{~g})$ was dissolved in distilled water $(5 \mathrm{ml})$ again, applied to a DEAE-52 $\left(\mathrm{OH}^{-}\right)$ anion exchange chromatography column $(2.6 \times 30 \mathrm{~cm})$ and subsequently eluted stepwise with deionized water followed by a $\mathrm{NaCl}$ gradient $(0 \rightarrow 1.0 \mathrm{~mol} / \mathrm{l})$ at a flow rate of $60 \mathrm{ml} / \mathrm{h}$. The fractions obtained by gradient $\mathrm{NaCl}$ elution were combined according to the total carbohydrate content and quantified by the Dubois et al (15) phenol-sulfuric acid method. The main peak was additionally fractionated on a Sephacryl S-400 column $(1.6 \times 80 \mathrm{~cm}$, GE Healthcare Bio-Sciences AB, Pittsburgh, PA, USA) and eluted with distilled water at a flow rate of $20 \mathrm{ml} / \mathrm{h}$ to yield a new fraction. The fractions were collected using the phenol-sulfuric acid method (15), with their absorption determined at $280 \mathrm{~nm}$ in the UV spectrum. The salt-eluted fraction was dialyzed and lyophilized, resulting in a white purified polysaccharide from S. nudus eggs, named SEP-S. A flowchart describing the isolation of the 2 polysaccharide fractions is presented in Fig. 1A. SEP-S is a homogeneous polysaccharide component composed of $\alpha$-D-glucan, with a low molecular weight of $9.33 \times 10^{5} \mathrm{Da}$, which differs from SEP. The endotoxin levels of SEP-S were determined using the E-TOXATE ${ }^{\mathrm{TM}}$ kit (Sigma-Aldrich; Merck Millipore). Test samples used in the study did not exhibit detectable levels of endotoxin within the sensitivity limit of the kit $(0.1-1.0 \mathrm{EU} / \mathrm{ml})$.

In vitro cell viability assay. Splenocyte proliferation was assayed using the MTT (Sigma-Aldrich; Merck Millipore, Darmstadt, Germany) method (16). The splenocyte proliferation level of the control group was designated as 1 , and the levels of the other groups were compared with it. The MTT method was additionally used to evaluate the antitumor properties of SEP-S against four cancer cell lines in vitro. Tumor A549, HepG2, H22 and B16 cells or MDCK cells were seeded in 96-well plates at a concentration of $5 \times 10^{3}$ cells/well, and cultured in RPMI-1640 or DMEM supplemented with $10 \%$ fetal calf serum. Subsequently, the cancer cells or MDCK cells were inoculated with SEP-S or cisplatin (at concentrations ranging from $0-500 \mu \mathrm{g} / \mathrm{ml}$ ) for $48 \mathrm{~h}$. The absorbance at $570 \mathrm{~nm}$ was determined using an ELISA reader (Bio-Rad Laboratories, Inc., Hercules, CA, USA). Cell viabilities were calculated using the following formula: Cell viability $(\%)=($ drug treatment-background)/(control-background) x100\%.

In vivo antitumor activity assay. To establish the murine solid tumor transplantation model, $\mathrm{H} 22$ ascites tumor cells $\left(2 \times 10^{7}\right.$ cells in $0.2 \mathrm{ml}$ normal saline) were subcutaneously injected into the right axillary region of ICR mice in all groups (17). Subsequently, $24 \mathrm{~h}$ following inoculation, the mice were divided randomly into 5 groups, each containing 12 mice. SEP-S was administered to each group at various dosages $(5,10$ and $20 \mathrm{mg} / \mathrm{kg}$ body weight). The positive control group received 5 -Fu at a dosage of $25 \mathrm{mg} / \mathrm{kg}$ body weight, and the vehicle control group was treated with normal saline. All the solutions were dissolved in saline, filtered through a $0.22 \mu \mathrm{m}$ millipore filter and administered daily via intravenous injection $(200 \mu \mathrm{l})$ for 12 days. The mouse weights were recorded following each drug administration. Mice were sacrificed by cervical dislocation $24 \mathrm{~h}$ subsequent to the final drug administration. Spleen, thymus and tumor weights in the mice were determined. The tumor inhibitory rate was calculated using the following formula: Tumor inhibitory rate $(\%)=\left(\mathrm{W}_{\text {Control }}-\mathrm{W}_{\text {Treated }}\right) / \mathrm{W}_{\text {Control }} \mathrm{x} 100 \% ; \mathrm{W}_{\text {Treated }}$ and $\mathrm{W}_{\text {Control }}$ were the average tumor weight of the treated and vehicle control mice, respectively. The thymus or spleen index was calculated as thymus or spleen weight divided by the body weight, respectively (18). Tumor and spleen samples from each group were fixed in $10 \%$ formalin and embedded in paraffin. Subsequently, $5 \mathrm{~mm}$ sections were stained with hematoxylin 
and eosin. Histological examinations were performed using an inverted fluorescence microscope (Olympus Corporation, Tokyo, Japan). To determine the life-prolonging effect of SEP-S, H22-bearing mice treated for 12 days with 5, 10 and $20 \mathrm{mg} / \mathrm{kg} /$ day of SEP-S were observed during the subsequent 17 days.

Cluster of differentiation (CD) $4^{+}$and $C D 8^{+} T$ lymphocytes determination in spleens and tumors from SEP-S-treated H22-bearing mice. Splenic lymphocytes from tumor-bearing ICR mice were prepared and incubated with $10 \mu \mathrm{l}$ anti-CD3-FITC (\#11-0032; $0.5 \mathrm{mg} / \mathrm{ml}$; dilution, 1:200), anti-CD4-FITC (\#11-0041; $0.5 \mathrm{mg} / \mathrm{ml}$; dilution, 1:200) or anti-CD8-FITC antibodies (\#12-0081; $0.2 \mathrm{mg} / \mathrm{ml}$; dilution, 1:80), all purchased from eBioscience Inc. (San Diego, CA, USA), for $30 \mathrm{~min}$ at room temperature. The cells were then washed twice with PBS and resuspended in $1 \%$ paraformaldehyde. The counts of $\mathrm{CD}^{+}, \mathrm{CD}^{+}$and $\mathrm{CD}^{+} \mathrm{T}$ lymphocytes were determined using a flow cytometer (BD Biosciences, San Jose, CA, USA) (10).

Cytotoxic activity assay of splenic CTLs from SEP-S-treated H22-bearing mice. The cytotoxic activities of the CTLs were assayed using the MTT method as previously described (19). Briefly, for CTL activity, splenic lymphocytes in each group were prepared as effector cells, and the ratios of effector cells to target H22 cells (E:T) were 40:1, 20:1 and 10:1. Subsequent to the cells being incubated at $37^{\circ} \mathrm{C}$ for $4 \mathrm{~h}$, the cellular cytotoxicity was determined as CTL activity $(\%)=\mathrm{OD}_{\mathrm{T}}-\left(\mathrm{OD}_{\mathrm{S}}-\mathrm{OD}_{\mathrm{E}}\right) / \mathrm{OD}_{\mathrm{T}} \mathrm{x} 100 \%$, where the optical density values were $\mathrm{OD}_{\mathrm{T}}$ for the target cell controls, $\mathrm{OD}_{\mathrm{S}}$ for the samples and $\mathrm{OD}_{\mathrm{E}}$ for the effector cell controls.

Anti-TLR2/4 antibody-blocking assays. To determine whether splenocyte proliferation stimulated by SEP-S was associated with the surface receptor TLR2/4, anti-TLR2/4 antibody-blocking assays were performed as previously described (11). Mouse splenocyte suspensions $\left(1 \times 10^{6}\right.$ cells $\left./ \mathrm{ml}\right)$ cultivated in 96-well plates were pre-treated with $5 \mu \mathrm{g} / \mathrm{ml}$ of the TLR2 or TLR4 monoclonal antibodies at $37^{\circ} \mathrm{C}$ for $1 \mathrm{~h}$, and then $200 \mu \mathrm{g} / \mathrm{ml} \mathrm{SEP-S}$ was added for $48 \mathrm{~h}$. Subsequent to incubation, the inhibition of splenocyte proliferation by anti-TLR2 and anti-TLR4 antibodies was determined using the MTT method.

Statistical analyses. The data were statistically analyzed using a student's $t$-test with Graphpad Prism 4.0 (Graphpad Software, Inc. La Jolla, CA). The data were analyzed using one-way analysis of variance, followed by Dunnett's test, to identify any differences among the control, drug-treated and antibody-treated groups. The results are presented as the mean \pm standard deviation. $\mathrm{P}<0.05$ was considered to indicate a statistically significant difference.

\section{Results}

Isolation and purification of SEP-S. Crude polysaccharide was prepared from $S$. nudus eggs by hot-water extraction, deproteination and ethanol precipitation. The crude polysaccharide was initially fractionated on a DEAE-52 cellulose column
(Fig. 1A). The elution curve indicated that the crude polysaccharide was composed of two major fractions (Fig. 1B). SEP-S was eluted with a linear gradient of $\mathrm{NaCl}(0-1.0 \mathrm{~mol} / \mathrm{l})$; it was a novel polysaccharide component, distinct from the previously reported SEP fraction eluted with distilled water (8). The purification procedure indicated that these two polysaccharide components had different binding properties toward the DEAE-52 column, possibly due to surface charge properties. SEP-S was additionally purified on a Sephacryl-400 column, and the elution curve was a single peak, as presented in Fig. 1C. The data revealed that SEP-S was a single and symmetrical peak on the high-performance liquid chromatography profile (Fig. 1D), with a purity of $99.0 \%$, indicating that it is a homogeneous polysaccharide. The yield of final purified SEP-S was $2.1 \%$ of the dry weight. Therefore, by using the SEP purification protocol with certain modifications, the present study identified a polysaccharide component, SEP-S, which may possess a negative charge, causing strong binding to the DEAE-52 column. In addition, SEP-S is a homogeneous polysaccharide component composed of $\alpha$-D-glucan, with a lower molecular weight of $9.33 \times 10^{5} \mathrm{Da}$, which differs from SEP.

SEP-S stimulates the proliferation of splenocytes and suppressed the growth of tumor cells in vitro. The mitogenic effect of SEP-S was initially examined using total spleen cells. As presented in Fig. 2A, SEP-S notably enhanced the proliferation of splenocytes at doses of 50 to $400 \mu \mathrm{g} / \mathrm{ml}$. At the dose of $400 \mu \mathrm{g} / \mathrm{ml}$, SEP-S stimulated splenocyte proliferation by 1.8 -fold, compared with the model control $(\mathrm{P}=0.0007)$, suggesting that SEP-S exerted a direct mitogenic effect on mouse splenocytes, which is increased, compared with that of SEP (P=0.0009). In addition, SEP-S $(400 \mu \mathrm{g} / \mathrm{ml})$ stimulated splenocyte proliferation in accordance to concanavalin A.

In total, the four A549, HepG2, H22 and B16 cancer cell lines were selected for assessing the potential antitumor activity of SEP-S in vitro using the MTT method. The tumor cells were treated with various concentrations of SEP-S (62.5, 125,250 and $500 \mu \mathrm{g} / \mathrm{ml}$ ), and the viability of all decreased in a dose-dependent manner, as presented in Fig. 2B. The inhibitory levels with $\mathrm{H} 22$ and A549 were $30.5 \%$ and $31.1 \%$, respectively, in response to SEP-S treatment of, $\leq 250 \mu \mathrm{g} / \mathrm{ml}$, and the inhibitory level with the HepG2 cancer cells was $25.7 \%$ at a concentration of $500 \mu \mathrm{g} / \mathrm{ml}$. Notably, SEP-S exhibited no direct cytotoxicity toward MDCK cells, as presented in Fig. 2C. These data indicate that SEP-S is a biological response modifier and may suppress the proliferation of various cancer cells while exhibiting no toxic effects toward normal cells, including MDCK, in vitro.

SEP-S effectively inhibits tumor growth in H22-bearing mice. To investigate whether SEP-S has in vivo antitumor activity, H22 xenograft tumors were excised from mice and weighed following 12 days of SEP-S pretreatment. As evident from Fig. 3A and B, injection with SEP-S at 5, 10 and $20 \mathrm{mg} / \mathrm{kg} /$ day significantly reduced tumor weight in a dose-dependent manner, with inhibition values of $38.8,50.7$ and $70.3 \%$, respectively. The marked inhibition of tumor growth in mice treated with $20 \mathrm{mg} / \mathrm{kg}$ SEP-S was comparable to that observed with 5 -Fu treatment $(69.6 \%)$. Additionally, the relative spleen and thymus indices of the SEP-S-treated groups were increased 

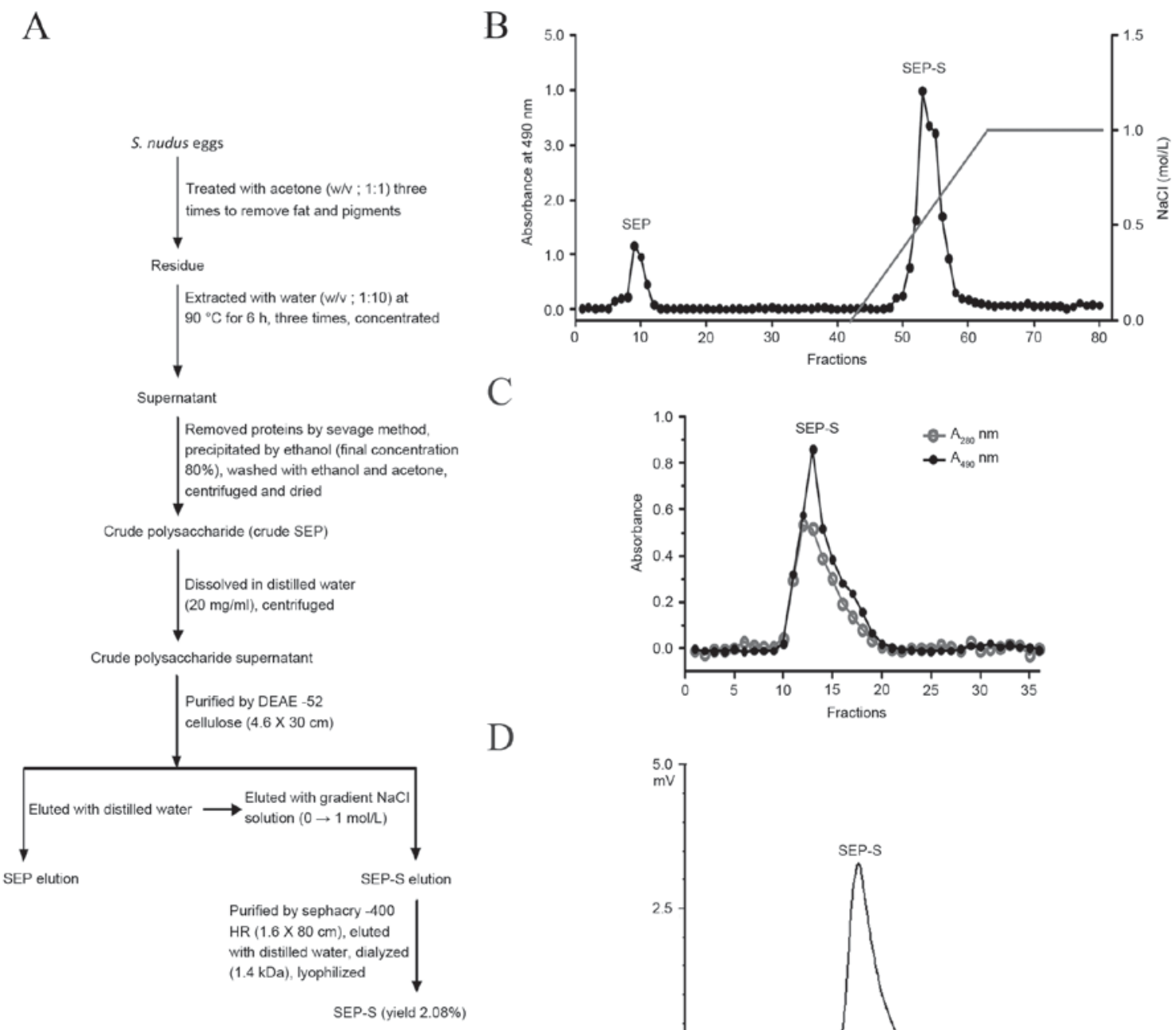

C

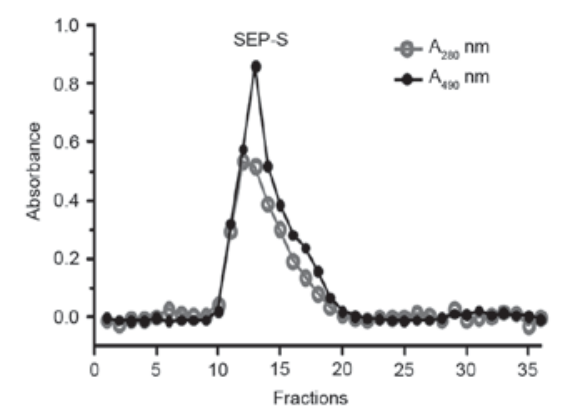

$\mathrm{D}$

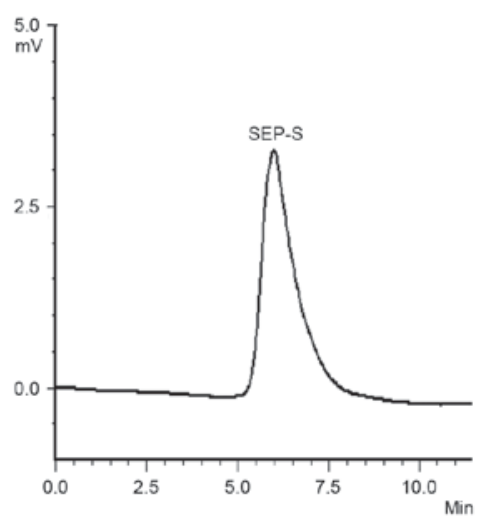

Figure 1. Isolation, purification and purity identification of a polysaccharide component (SEP-S) from S. nudus eggs. (A) Flowchart describing the extraction of the SEP-S and SEP fractions from S. nudus eggs. (B) Anion-exchange chromatography of the polysaccharides from $S$. nudus eggs, isolated by the DEAE-52 column. (C) Gel filtration chromatography of SEP-S on a Sephacry S-400 column. (D) High-performance liquid chromatography profile of SEP-S. S. nudus, Strongylocentrotus nudus; SEP-S, an eluant of NaCl solution gradient elution of Strongylocentrotus nudus egg polysaccharide; DEAE, diethylaminoethyl cellulose.

compared with those of the model groups [thymus indices: Control vs. SEP-S-treated group $(5 \mathrm{mg} / \mathrm{kg}), \mathrm{P}=0.0057$; control vs SEP-S-treated group $(10 \mathrm{mg} / \mathrm{kg}), \mathrm{P}=0.0062$; control vs . SEP-S-treated group $(20 \mathrm{mg} / \mathrm{kg}), \mathrm{P}=0.0073$; spleen indices: Control vs. SEP-S-treated group $(5 \mathrm{mg} / \mathrm{kg}), \mathrm{P}=0.0053$; control vs. SEP-S-treated group $(10 \mathrm{mg} / \mathrm{kg}), \mathrm{P}=0.0055$; control vs . SEP-S-treated group $(20 \mathrm{mg} / \mathrm{kg}), \mathrm{P}=0.0064]$. Consistent with the antitumor activity, at a dose of $20 \mathrm{mg} / \mathrm{kg} / \mathrm{day}$, these 2 indices increased by $\sim 3.6$ - and 2.5 -fold, respectively, compared with the model group (Fig. 3C and D). To additionally assess the antitumor and immunoregulatory effect of SEP-S on H22-bearing mice, tumor and spleen tissues from each group were subjected to histochemical examination. As presented in Fig. 3E, the tumor cells from the model control were arranged tightly with a large nucleus. By contrast, in the SEP-S-treated group, the tumor cells were arranged loosely with anomalous shapes and were either fragmented or lightly stained, which indicated necrotic morphology. In addition, the tumors of the SEP-S-treated group exhibited increased infiltration of lymphocyte populations, compared with the model control. Furthermore, SEP-S facilitated splenocyte multiplication, compared with the model control, particularly at the dose of $20 \mathrm{mg} / \mathrm{kg} /$ day, suggesting that SEP-S protects the immune organs against atrophy; this was coincident with an increase in the spleen index in SEP-S-treated mice.

SEP-S prolongs the survival period and maintains the body weight of H22-bearing mice. SEP-S treatment effectively increased the survival time of the H22 tumor-bearing mice. The average survival time of H22-bearing mice treated with SEP-S was extended $\sim 3$-fold, compared with that of the model group. The group treated with $20 \mathrm{mg} / \mathrm{kg} / \mathrm{day}$ of SEP-S was almost comparable to that treated with 5-Fu in terms of prolonging the survival period of $\mathrm{H} 22$ tumor-bearing mice 

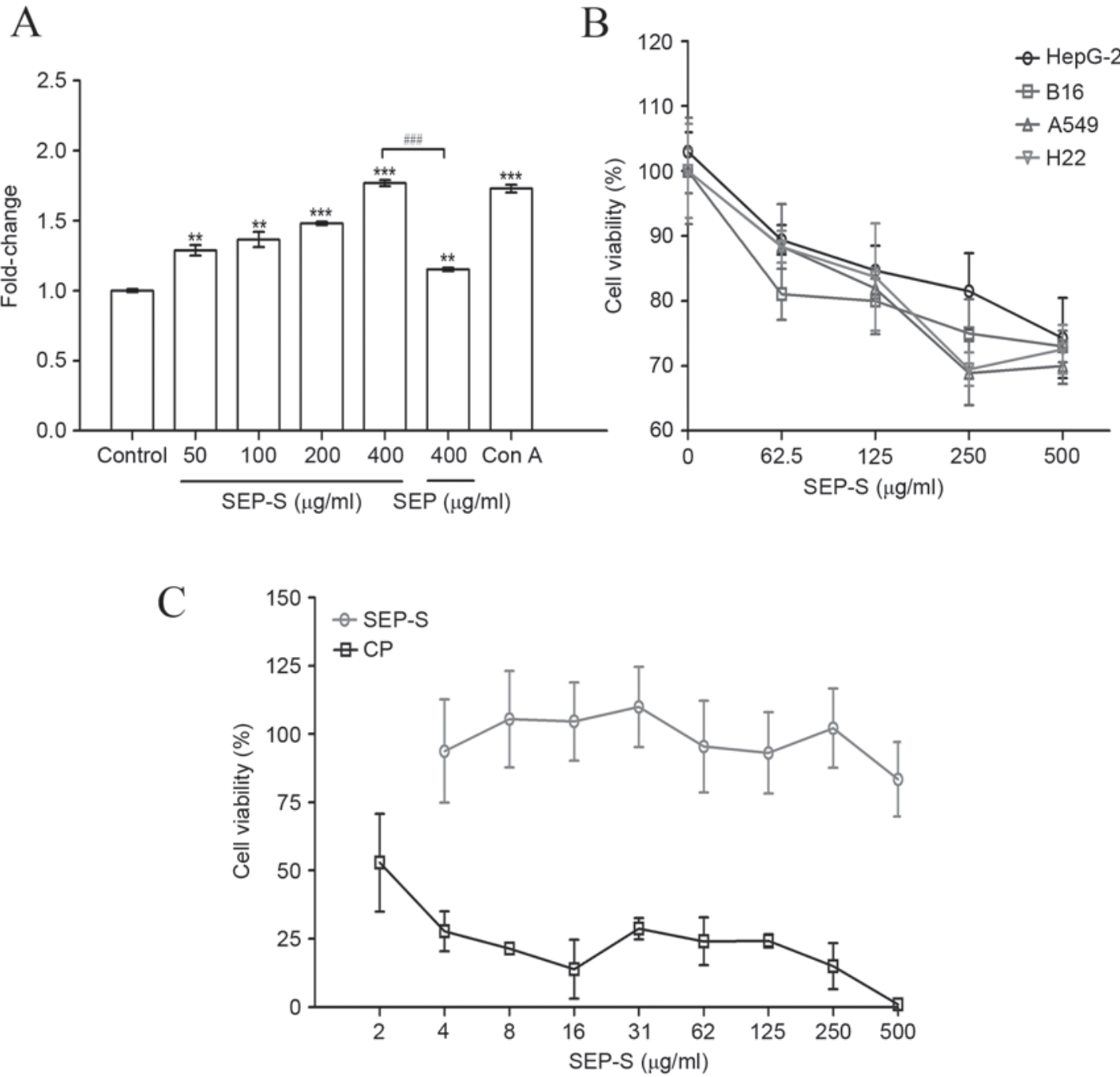

Figure 2. Effect of SEP-S on the proliferation of splenocytes and tumor cells in vitro. (A) SEP-S enhanced the proliferation of splenocytes at doses of 50-400 $\mu \mathrm{g} / \mathrm{ml}$. The cytotoxic effects of SEP-S against (B) the HepG2, B16, A549 and H22 tumor cell lines and (C) the MDCK normal cell line were investigated. SEP-S suppressed proliferation of the cancer cells but exhibited no cytotoxicity toward MDCK. The data are presented as the mean \pm standard deviation from triplicate wells. ${ }^{* *} \mathrm{P}<0.01$ and ${ }^{* * * *} \mathrm{P}<0.001$, compared with the model control; ${ }^{\# \# \#} \mathrm{P}<0.001$. SEP-S, an eluant of NaCl solution gradient elution of Strongylocentrotus nudus egg polysaccharide; CP, cisplatin.

(Fig. 4A). As for body weight, there was a protective effect in the SEP-S-treated groups (Fig. 4B), particularly at a dose of $5 \mathrm{mg} / \mathrm{kg} / \mathrm{day}$. Collectively, these results indicate that SEP-S treatment exerted beneficial effects in causing regression of tumor growth, enhancing immune function, extending the survival period and increasing the body weight of $\mathrm{H} 22$ tumor-bearing mice.

SEP-S upregulates T lymphocyte subsets from the spleen and tumor and enhances CTL activity in H22-bearing mice. To investigate the effects of SEP-S on cellular immunity, the counts of $\mathrm{CD}^{+}, \mathrm{CD}^{+}$and $\mathrm{CD} 8^{+} \mathrm{T}$ lymphocytes from the spleen and tumor were determined using flow cytometry. As illustrated in Fig. 5A and B, the percentage of the CD4 ${ }^{+}$ and $\mathrm{CD}^{+} \mathrm{T}$ lymphocytes was increased in the spleen and the tumor of the SEP-S-treated groups. The $20 \mathrm{mg} / \mathrm{kg} / \mathrm{day}$ SEP-S-treated group had significantly elevated proportions of $\mathrm{CD}^{+}$and $\mathrm{CD} 8^{+} \mathrm{T}$ lymphocyte subsets in the spleen $(\leq 29.5 \%$ and $24.8 \%$, respectively; $\left.\mathrm{CD}^{+}, \mathrm{P}=0.041 ; \mathrm{CD}^{+}, \mathrm{P}=0.0061\right)$ and a significantly elevated proportion of $\mathrm{CD} 4^{+} \mathrm{T}$ lymphocytes in the tumor $(\leq 2.7 \% ; \mathrm{P}=0.0063)$, whereas the $\mathrm{CD} 8^{+} \mathrm{T}$ lymphocyte proportion was not significantly elevated in the tumor (3.7\%; $\mathrm{P}=0.531$ ). The activity of CTLs from spleens of SEP-S-treated mice was markedly elevated in a ratio- and dose-dependent manner. In the $20 \mathrm{mg} / \mathrm{kg} / \mathrm{day}$ group, the CTL activities were increased to 33.6, 50.2 and 70.8\% at ratios of 10:1, 20:1 and 40:1 (E:T), respectively (Fig. 5C). These data indicated that SEP-S stimulated T lymphocyte immunity in vivo.

Splenocyte proliferation induced by SEP-S is inhibited by the TLR2 and TLR4 monoclonal antibodies. TLRs have been revealed to be expressed on various lymphocytes, and TLR2 and TLR 4 are expressed on T cells; TLR $2 / 4$ is generally considered to be the main receptor of polysaccharides $(20,21)$. To determine whether TLR2 or TLR4 was involved in the enhancement of splenocyte proliferation by SEP-S, blocking experiments were performed using anti-TLR 2 and anti-TLR4 antibodies. As illustrated in Fig. 6, mouse splenocyte proliferation in vitro was enhanced 1.5 -fold by $200 \mu \mathrm{g} / \mathrm{ml}$ SEP-S, compared with the control group, and it was significantly 


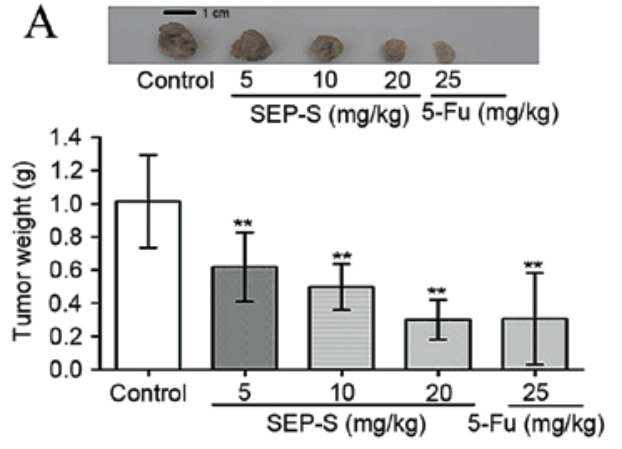

$\mathrm{C}$
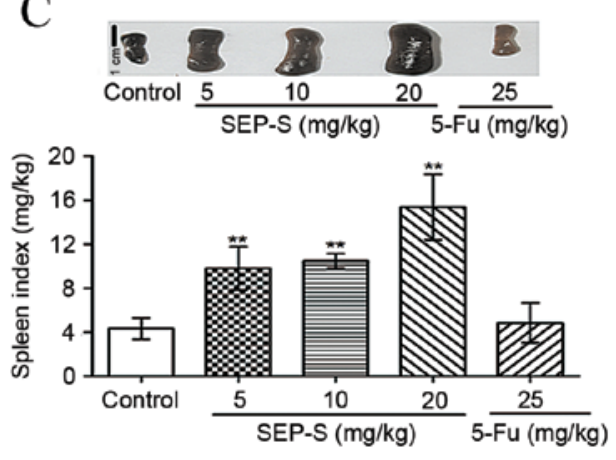

B

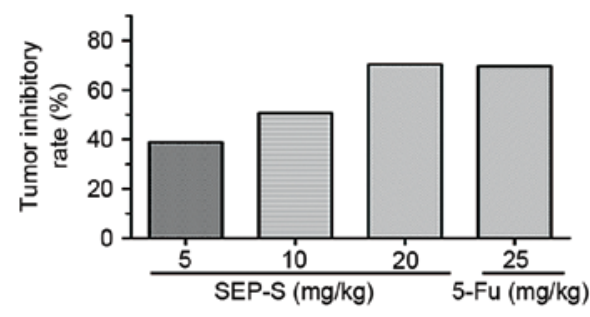

$\mathrm{D}$

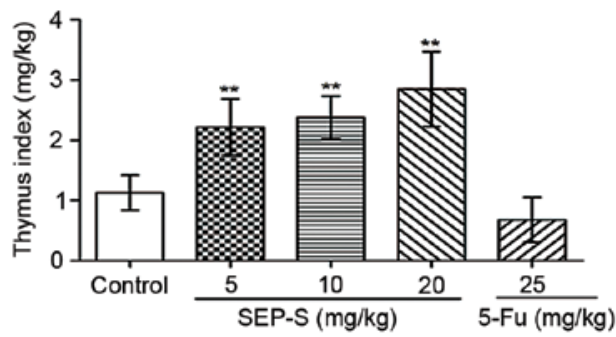

$\mathrm{E}$

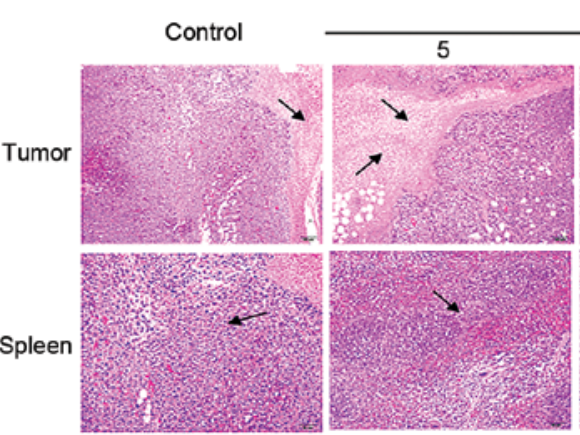

SEP-S $(\mathrm{mg} / \mathrm{kg} / \mathrm{d})$
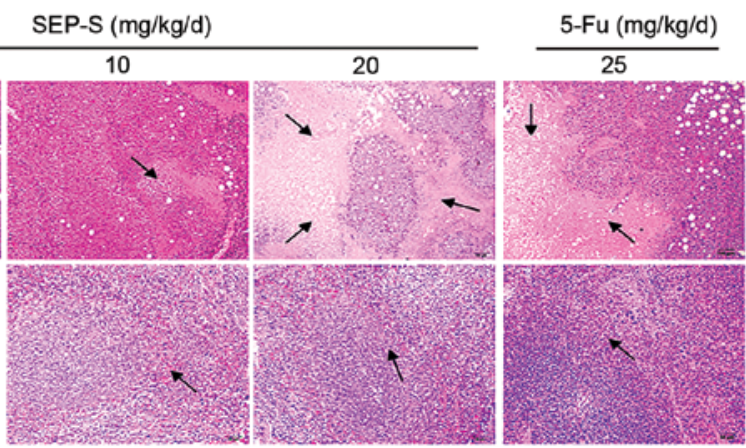

Figure 3. SEP-S effectively suppresses the growth of murine $\mathrm{H} 22$ in imprinting control region mice. SEP-S administration to H22 tumor-bearing mice induced a dose-dependent decrease in (A) tumor weight and (B) inhibition of tumor growth. The (C) spleen and (D) thymus indices were enhanced subsequent to SEP-S treatment. The values shown represent the mean \pm standard deviation, $n=12,{ }^{* *} \mathrm{P}<0.01$, compared with the control group. (E) Pathological changes in H22-bearing mice. Tumor tissues from H22-bearing mice treated with SEP-S (5, 10 and $20 \mathrm{mg} / \mathrm{kg} /$ day $)$ or 5 -Fu $(25 \mathrm{mg} / \mathrm{kg} / \mathrm{day})$ exhibited increased necrotic areas, compared with those from the control group. SEP-S protected the spleen from atrophy in mice from the model group. Representative micrographs are presented (tumor magnification, x100; spleen magnification x200; hematoxylin and eosin staining). SEP-S, an eluant of NaCl solution gradient elution of Strongylocentrotus nudus egg polysaccharide; H22, histocompatibility 22; 5-Fu, 5-Fluorouracil.

A

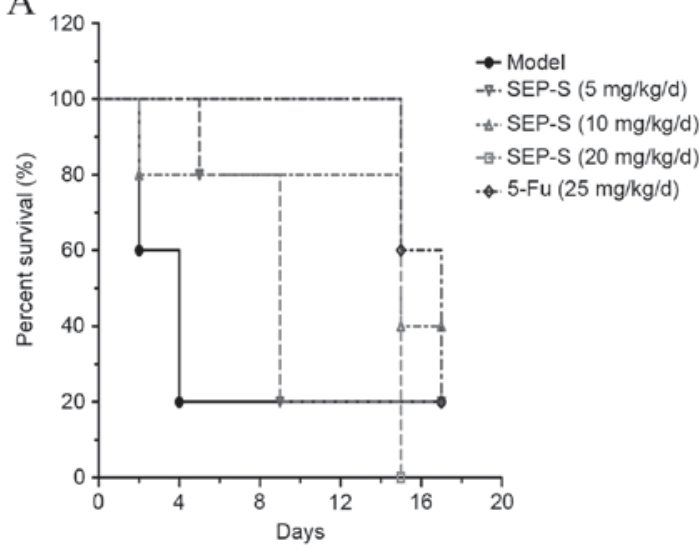

B

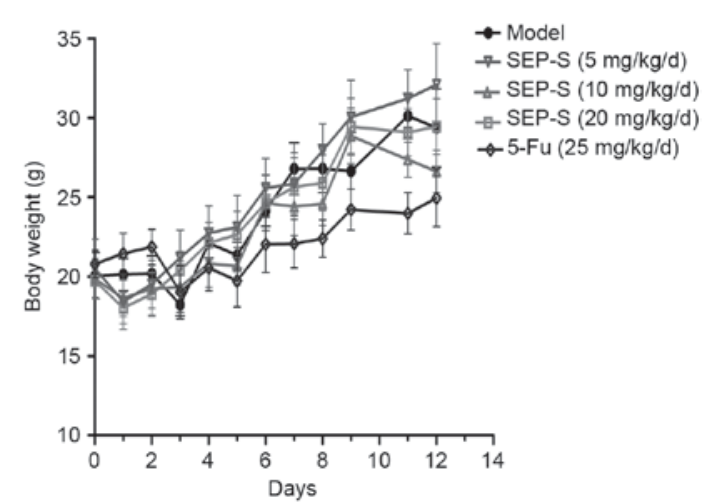

Figure 4. Effect of SEP-S on the survival rate and body weight of H22-bearing mice. (A) SEP-S prolonged the survival rate of H22 tumor-bearing mice. (B) SEP-S maintained the body weights of $\mathrm{H} 22$ tumor-bearing mice. SEP-S, an eluant of $\mathrm{NaCl}$ solution gradient elution of Strongylocentrotus nudus egg polysaccharide; $\mathrm{H} 22$, histocompatibility $22 ; 5$-Fu, 5-Fluorouracil. 
A

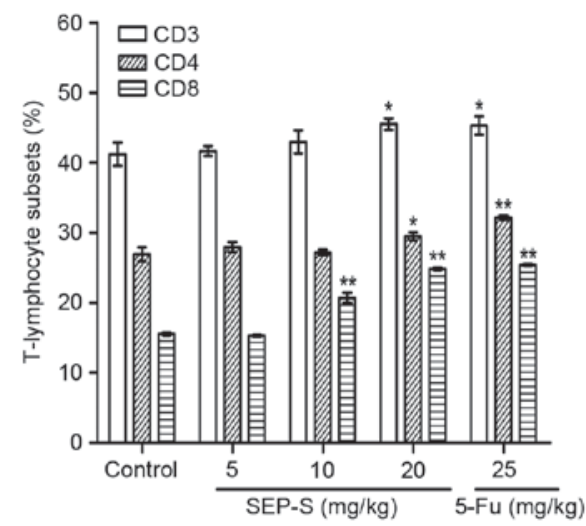

$\mathrm{B}$

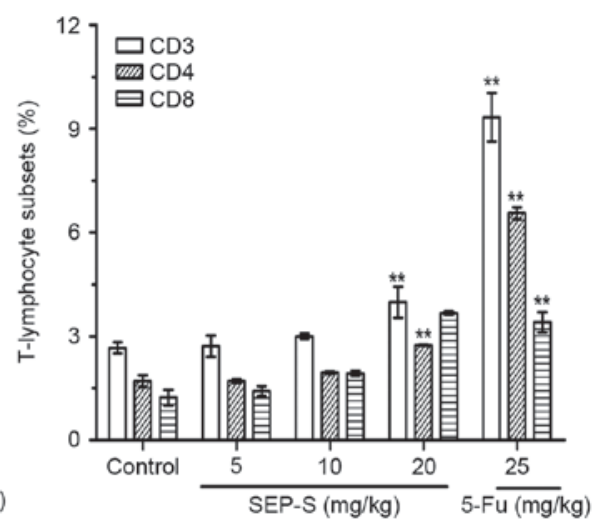

$\mathrm{C}$

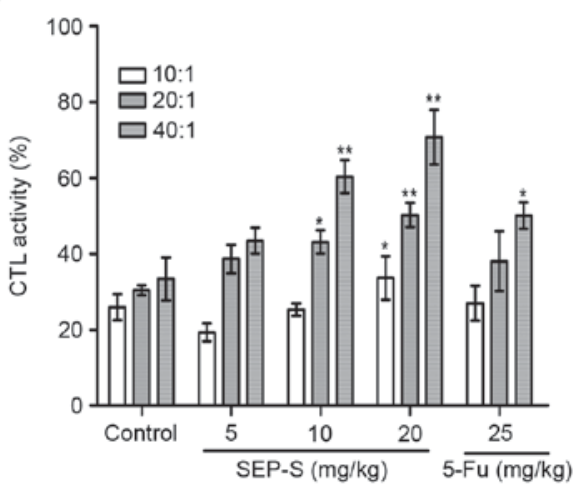

Figure 5. SEP-S upregulates T lymphocyte subsets from the spleen and tumor of H22-bearing mice. SEP-S (5, 10 and $20 \mathrm{mg} / \mathrm{kg} / \mathrm{day})$ increased the percentage of the $\mathrm{CD}^{+}$and $\mathrm{CD} 8^{+} \mathrm{T}-1 \mathrm{ymphocytes}$ from (A) the spleen and (B) tumor in a dose-dependent manner, compared with the model control. (C) SEP-S enhanced the activity of CTLs from the spleen of H22-bearing mice. SEP-S (5, 10 and $20 \mathrm{mg} / \mathrm{kg} / \mathrm{day})$ significantly enhanced the cytotoxic activity of splenocytes from H22-bearing mice at effector cell to target H22 cell ratios of 10:1, 20:1 and 40:1. Splenocytes were prepared and assayed for CTL activity using the MTT method. The values are presented as the mean \pm standard deviation from three separate experiments $(\mathrm{n}=12)$. ${ }^{*} \mathrm{P}<0.05$ and ${ }^{* *} \mathrm{P}<0.01$, compared with the model group. SEP-S, an eluant of $\mathrm{NaCl}$ solution gradient elution of Strongylocentrotus nudus egg polysaccharide; H22, histocompatibility 22; CD, cluster of differentiation; CTL, cytotoxic T lymphocyte; 5-Fu, 5-Fluorouracil.

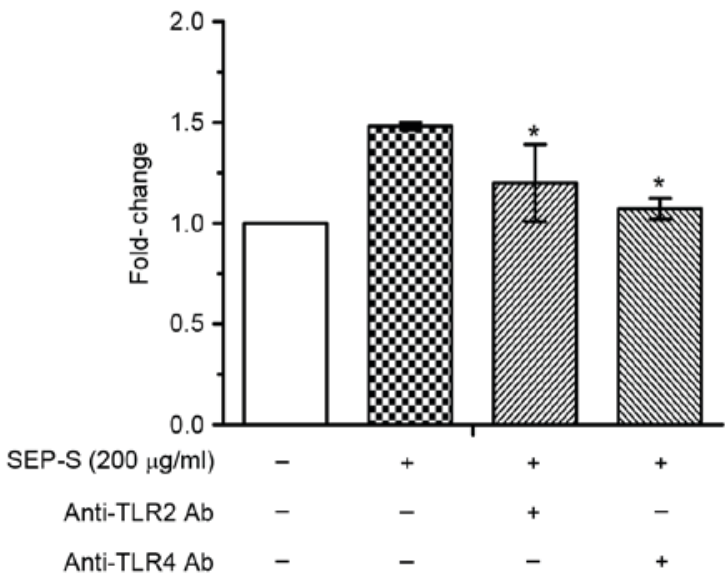

Figure 6. Splenocyte proliferation in vitro induced by SEP-S is inhibited by the TLR2 and TLR4 monoclonal antibodies. Splenocytes were harvested from imprinting control region mice and treated with SEP-S $(200 \mu \mathrm{g} / \mathrm{ml})$ subsequent to pretreatment with $5 \mu \mathrm{g} / \mathrm{ml}$ anti-TLR2 or anti-TLR4. "P $<0.05$, compared with the group treated only with SEP-S $(200 \mu \mathrm{g} / \mathrm{ml})$. SEP-S, an eluant of $\mathrm{NaCl}$ solution gradient elution of Strongylocentrotus nudus egg polysaccharide; TLR, toll-like receptor; Ab, antibody.

reduced by the anti-TLR2 or anti-TLR4 blocking antibody (anti-TLR2 vs. control, P=0.041; anti-TLR4 vs. control,
$\mathrm{P}=0.034)$. These data suggest that TLR 2 and TLR4 are involved in the stimulation of splenocyte proliferation by SEP-S.

\section{Discussion}

As a component of traditional Chinese medicine, S. nudus is able to prevent cardiovascular disease and enhance immunity $(22,23)$. In the present study, a novel salt-eluted polysaccharide component, SEP-S, with an average molecular weight of $9.33 \times 10^{5} \mathrm{Da}$, was successfully isolated and purified from $S$. nudus. Monosaccharide component analysis indicated that SEP-S was composed of glucose. The material obtained by $\mathrm{NaCl}$ gradient elution from the DEAE-52 cellulose column was additionally purified using Sephacryl S-400 to obtain a fraction, which was named SEP-S. In our previous study, the distilled water-eluted fraction of the DEAE-52 cellulose column, named SEP, had a molecular weight of $1.95 \times 10^{6} \mathrm{Da}$ and contained no protein or uronic acid (9). The immunoregulatory activities of polysaccharide depend on its structure, molecular weight and the number of branches (24). Varying molecular weights may lead to varying steric hindrances of the polysaccharides, resulting in altered receptor binding ability on the immune cells and differing immunological activities $(24,25)$. In certain cases, polysaccharides with larger molecular weights 
are less beneficial for crossing multiple membrane barriers to exert biological activities due to the greater volume $(24,25)$. It was observed that polysaccharides with varying molecular weights from instant coffee had differing in vitro immunostimulatory properties, and lower molecular weight fractions exhibited improved activity (25). As a lower molecular weight polysaccharide, which differs from SEP, SEP-S may possess increased biological activities.

The anti-hepatocarcinoma activity exhibited by SEP-S was an attractive property. SEP-S possessed antitumor activity in vitro while having no cytotoxicity toward normal cells, including MDCK. The present study additionally observed that SEP-S effectively inhibited $\mathrm{H} 22$ tumor growth in vivo with no cytotoxic effect, and the inhibitory rate was $\leq 70.3 \%$ at the dose $20 \mathrm{mg} / \mathrm{kg} /$ day. The tumor-inhibitory effect of SEP-S was more robust, compared with other polysaccharides, including SEP (10), schizophyllan and polysaccharide-K (26), the endo-polysaccharide of Phellinus igniarius (27) and the exopolysaccharide fraction of Cordyceps sinensis (28).

The currently proposed underlying mechanisms by which polysaccharides exert antitumor effects consist of direct tumor inhibition and immuno-enhancement (29). In the current study, SEP-S had a higher antitumor activity, compared with SEP, potentially due to its substantial cytotoxicity toward tumor cells and immune-regulation activity. The antitumor activity of polysaccharides may be affected by their monosaccharide composition, protein content, molecular mass and chain conformation (30). The in vitro antitumor assay revealed that SEP-S exhibited antitumor activity against the growth of HepG 2 cells to a certain extent. In addition, the cellular immune response effected by $\mathrm{T}$ cells has a central role in the generation and regulation of the immune response to tumor antigens (31). $\mathrm{T}$ cells are divided into subsets of $\mathrm{CD}^{+}{ }^{+}$or $\mathrm{CD} 8^{+}$, where $\mathrm{CD} 4$ $\mathrm{T}$ helper cells (Th) are important regulators of the immune system (32) and CD8 CTLs are major effectors of cell-mediated immunity (innate and adaptive immunity) and eliminate target tumor cells (33). SEP-S exerted a direct mitogenic effect on mouse splenocytes in a dose-dependent manner, which was marked, compared with that of SEP. Additionally, SEP-S not only significantly increased the percentages of $\mathrm{CD}^{+}$and $\mathrm{CD}^{+} \mathrm{T}$ cells, but markedly enhanced the cytotoxic activity of CTLs in H22-bearing mice. The enhanced percentage of $\mathrm{CD}^{+}$and $\mathrm{CD}^{+} \mathrm{T}$ cells additionally indicates that $\mathrm{Th}$ cells and CTLs were activated by SEP-S.

Polysaccharides isolated from a variety of sources were reported to activate immune cells via the TLR, CR3 and dectin-1 receptors. However, CR3 and dectin-1 are $\beta$-glucan-specific receptors (34-36). In the present study, it was observed that SEP-S mediated splenocyte proliferation via TLR2 and TLR4, similar to SEP (11). It is important to further study the underlying mechanisms by which SEP-S activates the immune system, particularly as SEP-S may be used as a protective immunotherapeutic agent for the treatment of liver cancer.

\section{Acknowledgements}

The present study was supported by The National Science and Technology Major Project Foundation of China (grant no. 2012ZX09102301-003), The Scientific and Technological Support \& Social Development Plan of Jiangsu Province (grant no. BE2011784) and The Priority Academic Program Development of Jiangsu Higher Education Institutions (PADA).

\section{References}

1. Sun YX: Structure and biological activities of the polysaccharide from the leaves, roots and fruits of Panax ginseng C.A. Meyer: An overview. Carbohydr Polym 85: 490-499, 2011.

2. Li S, Pan C, Xia W, Zhang W and Wu S: Structural characterization of the polysaccharide moiety of an aqueous glycopeptide from mannatide. Int J Biol Macromol 67: 351-359, 2014.

3. Jiang CX, Wang MC, Liu J, Gan D and Zeng XX: Extraction, preliminary characterization, antioxidant and anticancer activities in vitro of polysaccharides from Cyclina sinensis. Carbohydr Polym 84: 851-857, 2011.

4. Huang Y, Jiang C, Hu Y, Zhao X, Shi C, Yu Y, Liu C, Tao Y, Pan H, Feng Y, et al: Immunoenhancement effect of rehmannia glutinosa polysaccharide on lymphocyte proliferation and dendridtic cell. Carbohydr Polym 96: 516-521, 2013.

5. Jiang GX, Prasad KN, Jiang YM, Yang B, Jia YX and Sun J: Extraction and structural identification of alkali-soluble polysaccharides of longan (Dimocarpus longan Lour.) fruit pericarp. Innov Food Sci Emerg Technol 10: 638-642, 2009.

6. Yang B, Zhao MM, Prasad KN, Jiang GX and Jiang YM: Effect of methylation on the structure and radical scavenging activity of polysaccharides from longan (Dimocarpus longan Lour.) fruit pericarp. Food Chem 118: 364-368, 2010.

7. Swann JB and Smyth MJ: Immune surveillance of tumors. J Clin Invest 117: 1137-1146, 2007.

8. Ma Y, Xing Y, Mi H, Guo Z, Lu Y and Xi T: Extraction, preliminary characterization and immunostimulatory activity in vitro of a polysaccharide isolated from Strongylocentrotus nudus eggs. Carbohydr Polym 111: 576-583, 2014.

9. Liu CH, Lin Q, Gao Y, Ye L, Xing YY and Xi T: Characterization and antitumor activity of a polysaccharide from Strongylocentrotus nudus eggs. Carbohydr Polym 67: 313-318, 2007.

10. Wang M, Wang H, Tang Y, Kang D, Gao Y, Ke M, Dou J, Xi T and Zhou C: Effective inhibition of a Strongylocentrotus nudus eggs polysaccharide against hepatocellular carcinoma is mediated via immunoregulation in vivo. Immunol Lett 141: 74-82, 2011.

11. Ke M, Wang H, Zhang M, Tian Y, Wang Y, Li B, Yu J, Dou J, Xi T and Zhou C: The anti-lung cancer activity of SEP is mediated by the activation and cytotoxicity of NK cells via TLR $2 / 4$ in vivo: Biochem Pharma 89: 119-130, 2014.

12. Liu C, Xi T, Lin Q, Xing Y, Ye L, Luo X and Wang F: Immunomodulatory activity of polysaccharide isolated from Strongylocentrotus nudus eggs. Int Immunopharmacol 8: 1835-1841, 2008.

13. Wang H, Wang M, Chen J, Tang Y, Dou J, Yu J, Xi T and Zhou C: A polysaccharide from Strongylocentrotus nudus eggs protects against myelosuppression and immunosuppression in cyclophosphamide-treated mice. Int Immunopharmacol 11: 1946-1953, 2011.

14. Sevag MG, Lackman DB and Smolens J: The isolation of the components of streptococcal nucleoproteins in serologically active form. J Biol Chem 124: 425-436, 1938.

15. Dubois M, Gilles KA, Hamilton JK, Rebers PA and Smith F: Colorimetric method for determination of sugars and related substance. Anal Chem 28: 350-356, 1956.

16. Lee SM, Yoon MY and Park HR: Protective effects of paeonia lactiflora pall on hydrogen peroxide-induced apoptosis in PC12 cells. Biosci Biotechnol Biochem 72: 1272-1277, 2008.

17. Rashid S, Unyayar A, Mazmanci MA, McKeown SR, Banat IM and Worthington J: A study of anti-cancer effects of Funalia trogii in vitro and in vivo. Food Chem Toxicol 49: 1477-1483, 2011.

18. Sun LQ, Wang L and Zhou Y: Immunomodulation and antitumor activities of different-molecular-weight polysaccharides from Porphyridium cruentum. Carbohydr Polym 87: 1206-1210, 2012.

19. Xu HS, Wu YW, Xu SF, Sun HX, Chen FY and Yao L: Antitumor and immunomodulatory activity of polysaccharides from the roots of Actinidia eriantha. J Ethnopharmacol 125: 310-317, 2009.

20. Yoon YD, Han SB, Kang JS, Lee CW, Park SK, Lee HS, Kang JS and Kim HM: Toll-like receptor 4-dependent activation of macrophages by polysaccharide isolated from the radix of latycodon grandiflorum. Int Immunopharmacol 3: 1873-1882, 2003.

21. Yadav $M$ and Schorey JS: The $\beta$-glucan receptor dectin-1 functions together with TLR2 to mediate macrophage activation by mycobacteria. Blood 108: 3168-3175, 2006. 
22. Mourão PA and Pereira MS: Searching for alternatives to heparin: Sulfated fucans from marine invertebrates. Trends Cardiovasc Med 9: 225-232, 1999.

23. Sahara H, Ishikawa M, Takahashi N, Ohtani S, Sato N, Gasa S, Akino T and Kikuchi K: In vivo ant-tumour effect of 3'-sulphonoquinovosyl 1'-monoacylglyceride isolated from sea urchin (Strongylocentrotus intermedius) intestine. Br J Cancer 75: 324-332, 1997.

24. Miura NN, Adachi Y, Yadomae T, Tamura H, Tanaka S and Ohno N: Structure and biological activities of beta-glucans from yeast and mycelial forms of candida albicans. Microbiol Immunol 47: 173-182, 2003.

25. Passos CP, Cepeda MR, Ferreira SS, Nunes FM, Evtuguin DV, Madureira P, Vilanova M and Coimbra MA: Influence of molecular weight on in vitro immunostimulatory properties of instant coffee. Food Chem 161: 60-66, 2014.

26. Liu M, Li J, Kong F, Lin J and Gao Y: Induction of immunomodulating cytokines by a new polysaccharide-peptide complex from culture mycelia of Lentinus edodes. Immunopharmacology 40 : 187-198, 1998.

27. Chen J, Pan JZ, Li X, Zhou Y, Meng Q and Wang Q: Endo-polysaccharide of Phellinus igniarius exhibited anti-tumor effect through enhancement of cell mediated immunity. Int Immunopharmacol 11: 255-259, 2011.

28. Zhang W, Li J, Qiu S, Chen J and Zheng Y: Effects of the exopolysaccharide fraction (EPSF) from a cultivated Cordyceps sinensis on immunocytes of $\mathrm{H} 22$ tumor bearing mice. Fitoterapia 79 : $168-173,2008$

29. Fan L, Ding S, Ai L and Deng K: Antitumor and immunomodulatory activity of water-soluble polysaccharide from Inonotus obliquus. Carbohydr Polym 90: 870-874, 2012.
30. Zhang M, Cui SW, Cheung PCK and Wang Q: Antitumor polysaccharides from mushrooms: A review on their isolation process, structural characteristic and antitumor activity. Trends Food Sci Tech 18: 4-19, 2007.

31. Hong F, Yan J, Baran JT, Allendorf DJ, Hansen RD, Ostroff GR, Xing PX, Cheung NK and Ross GD: Mechanism by which orally administered beta-1, 3-glucans enhance the tumoricidal activity of antitumor monoclonal antibodies in murine tumor models. J Immunol 173: 797-806, 2004.

32. Shiku H: Importance of $\mathrm{CD} 4^{+}$helper T-cells in antitumor immunity. Int J Hematol 77: 435-438, 2003.

33. Sandel MH, Speetjens FM, Menon AG, Albertsson PA, Basse PH, Hokland M, Nagelkerke JF, Tollenaar RA, van de Velde CJ and Kuppen PJ: Natural killer cells infiltrating colorectal cancer and MHC class I expression. Mol Immunol 42: 541-546, 2005.

34. Han SB, Yoon YD, Ah HJ, Lee HS, Lee CW, Yoon WK, Park SK and Kim HM: Toll-like receptor-mediated activation of B cells and macrophages by polysaccharide isolated from cell culture of Acanthopanax senticosus. Int Immunopharmacol 3: 1301-1312, 2003.

35. Nair PK, Melnick SJ, Ramachandran R, Escalon E and Ramachandran C: Mechanism of macrophage activation by $(1,4)$-alpha-D-glucan isolated from Tinospora cordifolia. Int Immunopharmacol 6: 1815-1824, 2006.

36. Brown GD, Herre J, Williams DL, Willment JA, Marshall AS and Gordon S: Dectin-1 mediates the biological effects of beta-glucan. J Exp Med 197: 1119-1124, 2003. 